\title{
Succiniclasticum ruminis gen. nov., sp. nov., a Ruminal Bacterium Converting Succinate to Propionate as the Sole Energy-Yielding Mechanism
}

\author{
N. O. VAN GYLSWYK \\ Department of Animal Nutrition and Management, Swedish University of Agricultural Sciences, \\ Kungsängen Research Centre, S-753 23 Uppsala, Sweden
}

\begin{abstract}
A gram-negative, anaerobic, nonmotile, non-spore-forming, rod-shaped bacterium that fermented succinate quantitatively to propionate was isolated from a high dilution of rumen ingesta obtained from a dairy cow fed a production diet containing grass silage as the main roughage source. This organism did not grow on any of the following energy sources: 12 carbohydrates, pyruvate, lactate, 7 dicarboxylic acids, aspartate, citrate, and trans-aconitate. Both rumen fluid and yeast extract were necessary for good growth on succinate. The organism was negative for the following characteristics: production of propionate from threonine, protein digestion, sulfide production, nitrate reduction, catalase activity, and urease activity. There was no growth at $22^{\circ} \mathrm{C}$ and reduced growth at $45^{\circ} \mathrm{C}$ compared with growth at $39^{\circ} \mathrm{C}$. The DNA base composition was $52 \mathrm{~mol} \% \mathrm{G}+\mathrm{C}$. The complete $16 S$ rRNA sequence (EMBL accession number, X81137) was obtained, and the phylogenetic relationships of the organism were determined. The most closely related genera were the genera Acidaminococcus and Phascolarctobacterium. The name proposed for this bacterium is Succiniclasticum ruminis gen. nov., sp. nov.; the type strain is strain SE10 (= DSM 9236). Additional isolation attempts revealed that $S$. ruminis is a common inhabitant of the rumina of cows that are fed production diets and of cows on pasture.
\end{abstract}

A number of numerically and functionally important rumen bacteria produce succinate during fermentation of carbohydrates, but succinate is seldom detected in measurable amounts in rumina (8) because it is rapidly converted to propionate (2). Veillonella gazogenes (now Veillonella parvula) can convert succinate to propionate (9) but has not been considered generally important because it has been isolated in significant numbers only from sheep rumina. Wolin and Miller thought that Selenomonas ruminantium may be responsible for most of this activity in rumina (19), but this species requires carbohydrates in order to metabolize succinate. This could limit its succinate-degrading function in rumina, where there is always strong competition for readily fermentable carbohydrates. These considerations motivated me to search for other succinate-fermenting bacteria. I isolated a new bacterium with this property and propose in this paper that it should be named Succiniclasticum ruminis gen. nov., sp. nov.

\section{MATERIALS AND METHODS}

Media. All media were prepared under strictly anoxic conditions (15), and the gas phase (except where indicated otherwise) was $\mathrm{O}_{2}$-free $\mathrm{CO}_{2}$. Most of the medium components were heat sterilized; certain constituents were filter sterilized. The incubation temperature was usually $39^{\circ} \mathrm{C}$.

The basal medium contained (per liter) $0.225 \mathrm{~g}$ of $\mathrm{K}_{2} \mathrm{HPO}_{4}, 0.225 \mathrm{~g}$ of $\mathrm{KH}_{2} \mathrm{PO}_{4}, 0.45 \mathrm{~g}$ of $\mathrm{NaCl}, 0.45 \mathrm{~g}$ of $\left(\mathrm{NH}_{4}\right)_{2} \mathrm{SO}_{4}, 0.045 \mathrm{~g}$ of $\mathrm{CaCl}_{2}$ (anhydrous), $0.09 \mathrm{~g}$ of $\mathrm{MgSO}_{4} \cdot 7 \mathrm{H}_{2} \mathrm{O}, 6.36 \mathrm{~g}$ of $\mathrm{NaHCO}_{3}, 0.25 \mathrm{~g}$ of cysteine hydrochloride $\cdot \mathrm{H}_{2} \mathrm{O}, 0.25 \mathrm{~g}$ of $\mathrm{Na}_{2} \mathrm{~S}$ (hydrated), $0.005 \mathrm{~g}$ of indigo carmine, and $400 \mathrm{ml}$ of rumen fluid (strained through cheesecloth and centrifuged at $15,000 \times \mathrm{g}$ for $30 \mathrm{~min}$ ). Anoxic diluent contained the same ingredients except that rumen fluid and sulfide were not present and the concentration of cysteine was doubled. This diluent was used for serial dilution and for carrying inocula.

The basal medium was modified as follows for different purposes (the succinate used in the media described below was disodium succinate $\cdot 6 \mathrm{H}_{2} \mathrm{O}$ ). Enrichment medium contained $20 \mathrm{mM}$ succinate. Bacteria from enriched medium produced colonies on medium containing (per liter) $10 \mathrm{~g}$ of succinate, $1 \mathrm{~g}$ of yeast extract (Difco), and $20 \mathrm{~g}$ of agar. The maintenance medium used for slopes contained (per liter) $10 \mathrm{~g}$ of succinate, $5 \mathrm{~g}$ of yeast extract, and $15 \mathrm{~g}$ of agar. Poorly buffered medium contained $40 \mathrm{mM}$ succinate and $5 \mathrm{~g}$ of yeast extract per liter but no $\mathrm{NaHCO}_{3}$; the $\mathrm{Na}$ of $\mathrm{NaHCO}_{3}$ was replaced by the $\mathrm{Na}$ of $\mathrm{NaCl}$, the $\mathrm{pH}$ was adjusted to 6.8 with $\mathrm{HCl}$, and $\mathrm{CO}_{2}$ was replaced with $\mathrm{O}_{2}$-free $\mathrm{N}_{2}$. Gelatin liquefaction medium contained (per liter) $10 \mathrm{~g}$ of succinate, $5 \mathrm{~g}$ of yeast extract, and $120 \mathrm{~g}$ of gelatin. Casein digestion medium contained (per liter) $10 \mathrm{~g}$ of succinate, $5 \mathrm{~g}$ of yeast extract, $20 \mathrm{~g}$ of casein, and $20 \mathrm{~g}$ of agar but no cysteine or sulfide. Sulfide $\left(\mathrm{H}_{2} \mathrm{~S}\right)$ production medium contained (per liter) $10 \mathrm{~g}$ of succinate, $5 \mathrm{~g}$ of yeast extract, and $3 \mathrm{~g}$ of SIM medium (Difco); the cysteine concentration was doubled but no sulfide was added to this medium (a similar medium without rumen fluid was used for the same purpose). Nitrate reduction medium contained (per liter) $10 \mathrm{~g}$ of succinate and $5 \mathrm{~g}$ of yeast extract; a filter-sterilized $\mathrm{KNO}_{3}$ solution was added to a final concentration of $1 \mathrm{~g} /$ liter after sterilization, and cysteine, sulfide, and indigo carmine were omitted. Urease production medium contained (per liter) $10 \mathrm{~g}$ of succinate and $5 \mathrm{~g}$ of yeast extract, and a filter-sterilized urea solution was added to a final concentration of $15 \mathrm{~g} /$ liter after sterilization. The urease test was also done in poorly buffered medium (see above) performed with similar additions. Tests to determine the effect of $\mathrm{pH}$ on growth were performed in a medium similar to that used for the urease test except that urea was omitted.

In a number of tests I assessed growth by measuring optical density. When the media used for these tests were prepared, the rumen fluid was centrifuged at $50,000 \times g$ for $30 \mathrm{~min}$, indigo carmine was omitted, and $5 \mathrm{~g}$ of yeast extract per liter was included (modified basal medium). Energy sources were added as concentrated, filter-sterilized solutions. The final concentrations of acid substrates (as their sodium salts), aspartic acid, and threonine were $40 \mathrm{mM}, 40 \mathrm{mM}$, and $3 \mathrm{~g} /$ liter, respectively. When lactate was used, $20 \mathrm{mM}$ D-lactate and $20 \mathrm{mM}$ $\mathrm{L}$-lactate were added. The succinate concentrations tested were $20,40,70$, and $100 \mathrm{mM}$. Every other substrate (except where indicated otherwise) was added at a final concentration of $10 \mathrm{~g} /$ liter; glucose and mannose were also tested at a concentration of $2 \mathrm{~g} /$ liter. Susceptibility to oxygen was examined in modified basal medium containing $40 \mathrm{mM}$ succinate that was prepared with and without cysteine and sulfide, as well as in the latter medium in 13-ml tubes (containing 5 $\mathrm{ml}$ of medium) injected with $2 \mathrm{ml}$ of sterile air. The effects of different temperatures and the effect of Tween $80(0.2 \mathrm{~g} / \mathrm{liter})$ on growth were assessed in modified basal medium containing $40 \mathrm{mM}$ succinate. Bacteria were grown in modified basal medium containing $70 \mathrm{mM}$ succinate to determine the $\mathrm{G}+\mathrm{C}$ content.

Isolation. A sample of whole rumen ingesta was obtained from a lactating, rumen-fistulated cow fed a production diet containing grass silage as the main roughage source and was collected and treated as described previously (15).

Aliquots $(1 \mathrm{ml})$ of a $10^{-8}$ dilution in $5 \mathrm{ml}$ of enrichment medium were incubated, and portions of these preparations were transferred successively to fresh medium after 4,3 , and 1 days. Aliquots of diluted enriched cultures were grown in roll bottles containing succinate agar medium. After 3 days 10 colonies were picked. The strains obtained were subsequently reisolated and tested for growth in liquid succinate medium.

Characterization tests. For optical density measurements growth was monitored with a Novaspec II spectrophotometer (Pharmacia LKB) at $600 \mathrm{~nm}$ in glass tubes. Fermentation end products were determined by high-performance liquid chromatography (1), using pivalic acid as the internal standard. Except for the composition of the media, the tests to determine motility, catalase activity, urease activity, gelatin liquefaction, casein hydrolysis, $\mathrm{H}_{2} \mathrm{~S}$ production, produc- 
TABLE 1. Some properties of genera resembling strain SE $10^{\mathrm{T}}$ either phenotypically or genotypically ${ }^{a}$

\begin{tabular}{|c|c|c|c|c|}
\hline Taxon & Morphology & $\begin{array}{l}\mathrm{G}+\mathrm{C} \text { content of } \\
\text { DNA }(\text { mol } \%)\end{array}$ & $\begin{array}{l}\text { Succinic acid fermented } \\
\text { (propionate produced) }\end{array}$ & $\begin{array}{l}\text { Amino acids and peptides } \\
\text { used as energy sources }\end{array}$ \\
\hline $\mathrm{SE} 10^{\mathrm{T}}$ & $\begin{array}{l}\text { Short rods, limited branching on } \\
\text { some media }\end{array}$ & 52 & + & - \\
\hline Phascolarctobacterium & Short and long branched rods & $41-42$ & + & - \\
\hline Acidaminococcus & Cocci & 56 & - & + \\
\hline Propionigenium & Short rods & 34 & + & - \\
\hline
\end{tabular}

${ }^{a}$ None of the taxa is motile, produces spores, or ferments carbohydrates.

tion of propionate from threonine, and nitrate reduction (with sulfanilic acid and dimethyl-alpha-naphthylamine as reagents) were performed as recommended by Holdeman et al. (7).

$\mathrm{G}+\mathrm{C}$ content was estimated as previously described (17). DNAs from Escherichia coli B, Micrococcus luteus (Micrococcus lysodeikticus), and calf thymus (all obtained from Sigma) were used as calibration standards.

All determinations were done at least in duplicate.

Inocula. Inocula $(0.1 \mathrm{ml} / 5 \mathrm{ml}$ of medium) for tests were grown on succinate maintenance slopes for about $48 \mathrm{~h}$, and the organisms were rinsed from the agar surfaces with anoxic diluent; the organisms from several slopes were pooled. A control culture grown in basal medium containing yeast extract and succinate was included to ensure that the inocula were viable.

Phylogenetic analysis. Genomic DNA extraction, PCR-mediated amplification of the $16 \mathrm{~S}$ ribosomal DNA, and purification of PCR products were carried out as described previously $(11,12)$. Purified PCR products were sequenced by using a Taq Dye-Deoxy Terminator Cycle sequencing kit (Applied Biosystems, Weiterstadt, Hessen, Germany) as recommended by the manufacturer. Sequence reaction mixtures were electrophoresed by using an Applied Biosystems mode 373A DNA sequencer. The $16 \mathrm{~S}$ ribosomal DNA sequence was manually aligned with representative sequences of members of the Clostridium-Bacillus line of descent.

Pairwise evolutionary distances were computed by using the correction of Jukes and Cantor (10). The least-squares distance method of DeSoete (5) was used to construct a phylogenetic dendrogram from distance matrix data.

Nucleotide sequence accession number. The nucleotide sequence determined in this study has been deposited in the EMBL database under accession no. X81137.

\section{RESULTS AND DISCUSSION}

A strain isolated from enrichment medium that had been inoculated with a $10^{-8}$ dilution of whole rumen ingesta was able to grow on succinate as the sole energy source. This strain, strain SE $10^{\mathrm{T}}$ ( $\mathrm{T}=$ type strain), was characterized. Strain SE $10^{\mathrm{T}}$ cells were gram-negative, nonmotile, non-spore-forming, short rods that grew in the absence of oxygen at temperatures prevailing in the rumen. Of the substrates tested, only succinate supported growth, and propionate was the only end product detected. Negative results were obtained for a variety of tests (see below).

Relatedness to other taxa. Some of the characteristics that distinguish taxa which have phenotypic or genotypic properties similar to those of SE $10^{\mathrm{T}}$ are summarized in Table 1 . Strain SE $10^{\mathrm{T}}$ differs from Propionigenium modestum (13) in its inability to grow on pyruvate, oxaloacetate, fumarate, malate, or aspartate; Propionigenium modestum ferments fumarate, malate, and aspartate only after lag periods of 4 to 8 days. Colonies of Propionigenium modestum are yellowish, while colonies of SE $10^{\mathrm{T}}$ are colorless. Whereas Propionigenium modestum can grow at $15^{\circ} \mathrm{C}$, strain $\mathrm{SE} 10^{\mathrm{T}}$ cannot grow at $22^{\circ} \mathrm{C}$. SE $10^{\mathrm{T}}$ differs from Acidaminococcus fermentans (3) in that it cannot utilize amino acids and peptides as main energy sources or ferment citrate and trans-aconitate. Of the phenotypic characteristics that have been determined, the only one that distinguishes SE $10^{\mathrm{T}}$ from Phascolarctobacterium faecium (4) is cell morphology. While Phascolarctobacterium faecium can produce long branched cells, only very limited branching (V shapes) was observed with SE $10^{\mathrm{T}}$ under certain conditions (6). Of the energy sources examined, only succinate is fermented by Phascolarctobacterium faecium and SE $10^{\mathrm{T}}$, and fumarate inhibits the growth of both organisms. The dendrogram (Fig. 1), based on 16S rRNA sequence comparisons, shows that SE $10^{\mathrm{T}}$ is most closely related to Phascolarctobacterium faecium and $A$. fermentans. The $\mathrm{G}+\mathrm{C}$ content of $\mathrm{SE} 10^{\mathrm{T}}$ is closer to that of $A$. fermentans than to that of Phascolarctobacterium faecium (Table 1). Considering the phenotypic similarity of Phascolarctobacterium faecium and $\mathrm{SE} 10^{\mathrm{T}}$, differentiation of these taxa rests largely on the difference in $\mathrm{G}+\mathrm{C}$ contents and on the level of $16 \mathrm{~S}$ rRNA sequence similarity, which is not greater than $92.7 \%$, as shown in Table 2. Therefore, I propose that strain SE $10^{\mathrm{T}}$ should be placed in a new genus.

Description of Succiniclasticum gen. nov. Succiniclasticum (Suc.cin.i.clas'ti.cum. L. adj. succinicus, succinic; Gr. v. klao, to break; L. adj. clasticum, breaking; L. neut. n. Succiniclasticum, breaking or splitting succinic acid). The genus is characterized by not being able to ferment carbohydrates, amino acids, or mono-, di-, and tricarboxylic acids other than succinate, which is converted to propionate. Members of this genus are not proteolytic and do not produce catalase or urease or reduce nitrate. Cells are not extensively branched.

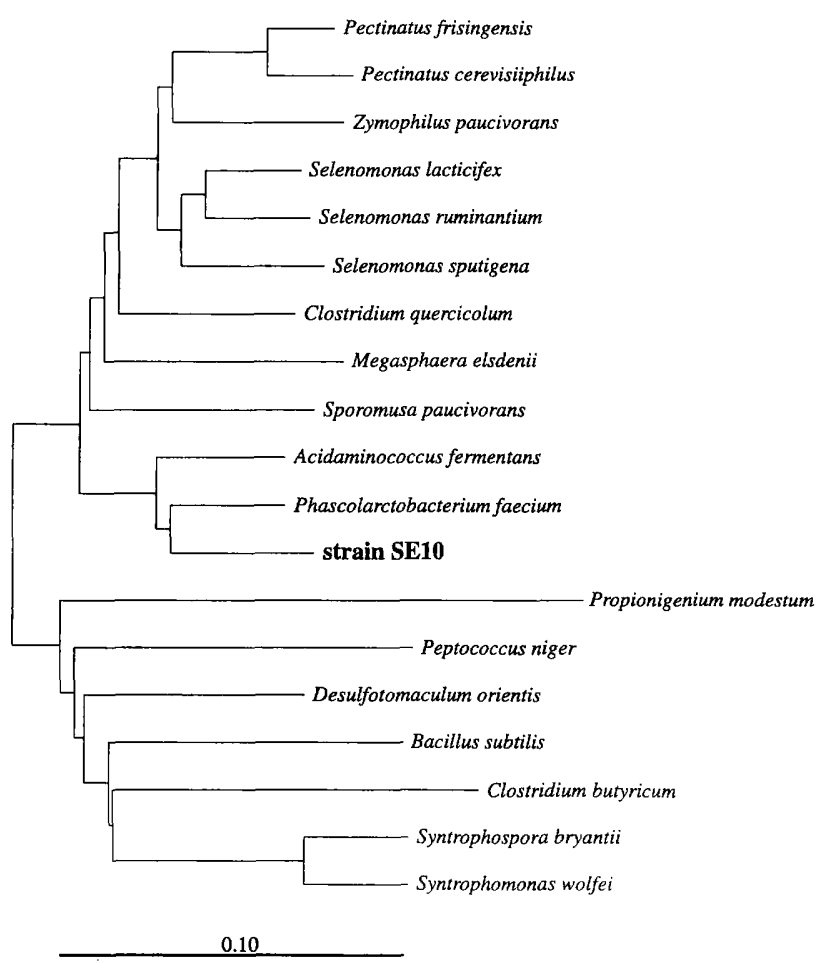

FIG. 1. Phylogenetic dendrogram showing the position of strain SE $10^{\mathrm{T}}$ within the radiation of the Sporomusa group of the Clostridium-Bacillus subphylum. $\mathrm{Bar}=10$ inferred nucleotide substitutions per 100 nucleotides. 
TABLE 2. Levels of $16 \mathrm{~S}$ ribosomal DNA similarity between strain SE $10^{\mathrm{T}}$ and related taxa

\begin{tabular}{|c|c|c|c|c|c|c|c|c|c|c|c|c|c|c|c|c|c|c|}
\hline \multirow[b]{2}{*}{ Species } & \multicolumn{18}{|c|}{$\%$ Similarity } \\
\hline & 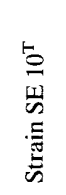 & 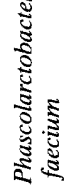 & 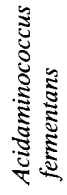 & 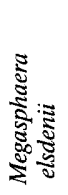 & 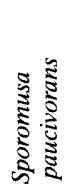 & 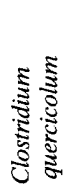 & 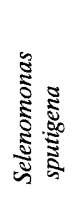 & 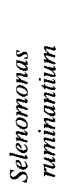 & 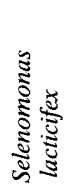 & 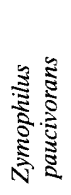 & 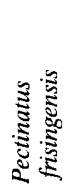 & 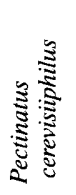 & 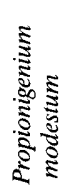 & 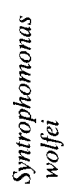 & 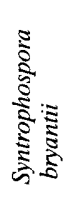 & 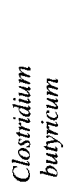 & 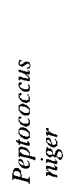 & 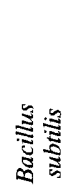 \\
\hline Phascolarctobacterium faecium & 92.7 & & & & & & & & & & & & & & & & & \\
\hline Acidaminococcus fermentans & 91.4 & 93.5 & & & & & & & & & & & & & & & & \\
\hline Megasphaera elsdenii & 86.4 & 87.3 & 86.9 & & & & & & & & & & & & & & & \\
\hline Sporomusa paucivorans & 87.0 & 89.0 & 88.6 & 85.9 & & & & & & & & & & & & & & \\
\hline Clostridium quercicolum & 88.5 & 88.6 & 88.0 & 88.2 & 90.0 & & & & & & & & & & & & & \\
\hline Selenomonas sputigena & 87.6 & 87.9 & 89.0 & 87.5 & 86.9 & 89.7 & & & & & & & & & & & & \\
\hline Selenomonas ruminantium & 87.0 & 88.0 & 87.6 & 87.0 & 87.1 & 89.0 & 93.1 & & & & & & & & & & & \\
\hline Selenomonas lacticifex & 86.9 & 88.0 & 88.8 & 88.3 & 87.8 & 90.4 & 91.9 & 94.4 & & & & & & & & & & \\
\hline Pectinatus frisingensis & 87.7 & 87.5 & 86.7 & 87.5 & 88.8 & 89.1 & 89.9 & 90.7 & 90.4 & 90.1 & & & & & & & & \\
\hline Pectinatus cerevisiiphilus & 86.6 & 86.1 & 86.1 & 87.7 & 87.2 & 88.2 & 91.0 & 90.0 & 89.8 & 90.8 & 95.5 & & & & & & & \\
\hline Propionigenium modestum & 79.9 & 80.0 & 79.6 & 79.5 & 77.3 & 78.2 & 77.1 & 77.9 & 78.5 & 76.7 & 77.7 & 76.6 & & & & & & \\
\hline Syntrophomonas wolfei & 81.6 & 82.3 & 82.8 & 81.5 & 81.2 & 82.0 & 81.9 & 83.3 & 83.5 & 81.5 & 81.7 & 81.9 & 78.4 & & & & & \\
\hline Syntrophospora bryantii & 81.5 & 81.9 & 82.7 & 81.6 & 81.8 & 82.0 & 81.7 & 83.4 & 82.8 & 81.5 & 81.8 & 81.6 & 78.3 & 94.1 & & & & \\
\hline Clostridium butyricum & 80.0 & 80.5 & 82.0 & 79.5 & 80.8 & 80.1 & 80.2 & 81.4 & 81.1 & 80.0 & 80.5 & 80.0 & 77.7 & 81.9 & 83.7 & & & \\
\hline Peptococcus niger & 81.8 & 82.8 & 83.5 & 83.5 & 81.2 & 82.3 & 82.3 & 82.9 & 82.6 & 81.2 & 80.3 & 81.4 & 77.2 & 83.3 & 83.1 & 80.6 & & \\
\hline Bacillus subtilis & 82.5 & 82.1 & 82.9 & 80.8 & 83.3 & 83.3 & 81.7 & 82.8 & 83.3 & 81.8 & 82.3 & 81.2 & 78.4 & 84.4 & 84.0 & 83.2 & 82.0 & \\
\hline Desulfotomaculum orientis & 84.4 & 85.1 & 83.7 & 84.2 & 86.2 & 85.6 & 84.8 & 85.4 & 84.8 & 83.2 & 84.2 & 83.4 & 80.3 & 85.9 & 85.8 & 83.0 & 85.2 & 86.4 \\
\hline
\end{tabular}

Description of Succiniclasticum ruminis sp. nov. Succiniclasticum ruminis (ru'mi.nis. L. neut. gen. n. ruminis, of the rumen). Cells are gram-negative and non-motile, do not produce spores, and are short rods which are 0.3 to $0.5 \mu \mathrm{m}$ wide and up to $1.8 \mu \mathrm{m}$ long (Fig. 2). The thicker rods tend to have rounded ends, while the narrower ones often have one end, or occasionally both ends, somewhat tapered and can be slightly curved. Large clumps of cells are often observed in liquid media or in the water of syneresis of cultures grown on agar slopes. These clumps are easily dispersed by shaking. After incubation on rumen fluid-succinate agar slopes for about $18 \mathrm{~h}$, surface colonies have diameters of up to $0.5 \mathrm{~mm}$. They are somewhat irregularly round with smooth edges, convex, practically colorless, and slightly opaque with a glistening appearance. Submerged colonies that develop after inoculation into molten agar are lens-shaped discs.

Growth characteristics. The following substrates do not support growth: glucose, galactose, mannose, rhamnose, fructose, xylose, arabinose, maltose, cellobiose, lactose, sucrose, treha-

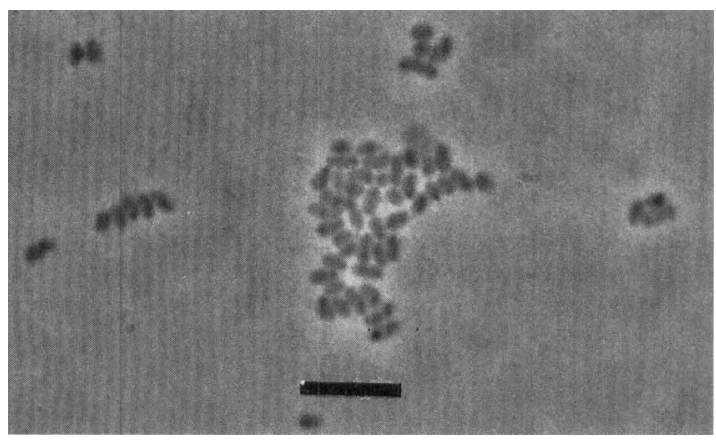

FIG. 2. Phase-contrast micrograph of Succiniclasticum ruminis $\mathrm{SE} 10^{\mathrm{T}}$ cells on a slide covered with agar. $\mathrm{Bar}=5 \mu \mathrm{m}$. lose, mannitol, glycerol, aspartic acid, the sodium salts of DLlactic and pyruvic acids, the disodium salts of oxalic, malonic, oxaloacetic, malic, fumaric, glutaric, and methylmalonic acids, the trisodium salts of citric and trans-aconitic acids, and yeast extract (which contains amino acids). Prolonged incubation ( 9 days) with fumarate, malate, aspartate, citrate, or trans-aconitate does not induce utilization. When acetate and butyrate are present in the rumen fluid of the medium, they are not assimilated to a measurable extent. Succinate is the only substrate tested that is fermented. Growth in the presence of $40 \mathrm{mM}$ succinate plus $10 \mathrm{mM}$ fumarate gives about the same maximal optical density as growth in the presence of succinate alone, but the maximal value is reached 1 to $2 \mathrm{~h}$ later. Very little growth occurs in medium containing $40 \mathrm{mM}$ succinate and 40 $\mathrm{mM}$ fumarate. There is very little growth in medium from which either rumen fluid or yeast extract is omitted (Fig. 3). Succinate concentrations of 40,70 , and $100 \mathrm{mM}$ result in progressively slower growth, but the final optical densities are correspondingly higher. Succinate is converted quantitatively to propionate, and no other end products are detected. $\mathrm{CO}_{2}$ is probably released, but $\mathrm{CO}_{2}$ release has not been measured. Growth in medium from which $\mathrm{CO}_{2}$ and $\mathrm{NaHCO}_{3}$ are omitted (poorly buffered medium with $\mathrm{NaCl}$ added) is appreciably less (the optical density is one-half as great) and slower than growth in medium containing $\mathrm{CO}_{2}$ and $\mathrm{NaHCO}_{3}$ (well-buffered medium). This could be due to $\mathrm{pH}$. In well-buffered medium, which contains $40 \mathrm{mM}$ succinate, the $\mathrm{pH}$ increases about $0.1 \mathrm{U}$, while the $\mathrm{pH}$ increases about $0.5 \mathrm{U}$ in poorly buffered medium after growth has ceased. Growth in medium prepared under anoxic conditions is about the same irrespective of whether a reducing agent (cysteine or sulfide) is added. However, when air is added to medium without a reducing agent, little growth occurs. At $39^{\circ} \mathrm{C}$ the maximum optical density is about twice the optical density at $45^{\circ} \mathrm{C}$ after about the same period of incubation. There is no growth at $22^{\circ} \mathrm{C}$. Tween 80 has no effect on growth. 


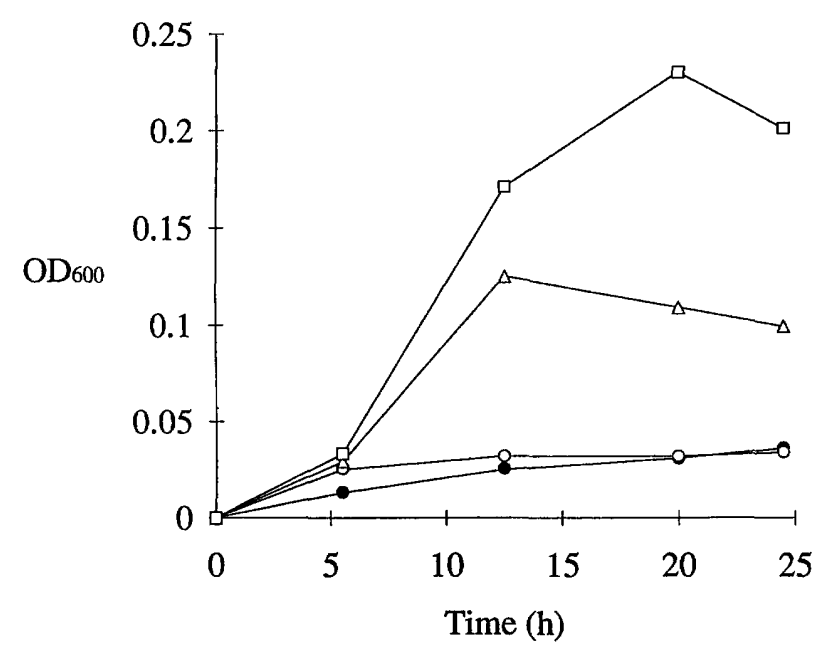

FIG. 3. Effect of yeast extract and concentration of succinate on the growth of Succiniclasticum ruminis SE $10^{\mathrm{T}}$ in medium containing $40 \%$ rumen fluid. Symbols: no yeast extract, $40 \mathrm{mM}$ succinate; $0,0.5 \%$ yeast extract, no succinate; $\triangle, 20 \mathrm{mM}$ succinate; $\square, 40 \mathrm{mM}$ succinate. $\mathrm{OD}_{600}$, optical density at $600 \mathrm{~nm}$.

Characterization tests and $\mathbf{G}+\mathbf{C}$ content. Strain $\mathrm{SE} 10^{\mathrm{T}}$ is not proteolytic; it neither liquefies gelatin nor hydrolyzes casein, and it does not produce $\mathrm{H}_{2} \mathrm{~S}$. Propionate is not formed from threonine. It does not produce catalase or urease or reduce nitrate. The $\mathrm{G}+\mathrm{C}$ content of the DNA is about 52 mol\% (values for three separate determinations: 51.1, 52.0, and $52.2 \mathrm{~mol} \%$ ).

Strain SE $10^{\mathrm{T}}$ is the type strain and has been deposited in the Deutsche Sammlung von Mikroorganismen und Zellkulturen as strain DSM 9236.

Isolation of other strains. Following the characterization of the unusual bacterium described above, I isolated bacteria having similar properties from the rumina of cows fed production diets containing silage or cows on pasture (16). I concluded that this organism is common in the rumen biota. Two of these bacterial strains are being characterized now. One of them was isolated from rumen ingesta $\left(2 \times 10^{-7}\right.$ dilution $)$ from a silage-fed cow different from the cow from which $\mathrm{SE}$ $10^{\mathrm{T}}$ was isolated, while the other was isolated from a cow $\left(10^{-8}\right.$ dilution of ingesta) on pasture supplemented with concentrate.

Role in rumen digestion. The relevance of Succiniclasticum ruminis clearly lies in the fact that this organism specializes in fermenting succinate and converting it quantitatively to propionate, the most important precursor of glucose in ruminants. The low energy yield when anaerobes convert succinate to propionate (14) should make this bacterium highly efficient in this conversion (there is a high rate of substrate turnover for a low rate of cell growth). Despite this, Succiniclasticum ruminis appears to occur in high numbers (at least $10^{8}$ cells per $g$ of ingesta) in the rumina of cows fed production diets containing grass silage (and usually about an equal amount of concentrate on a dry matter basis) as the main roughage source and in the rumina of cows on pasture. This implies that the growth rate of this organism is high enough so that the organism can compete successfully for essential growth factors and may depend on limited competition for succinate from other bacteria. The level of succinate production in the rumina of cows fed grass silage diets is probably high because the level of Prevotella ruminicola, a succinate producer, tends to be greater than $50 \%$ (15) of the "total culturable" bacteria and that of cows on pasture tends to be greater than $40 \%$ (16). Because Succiniclasticum ruminis has not been detected in ruminants fed other diets, it is possible that this organism typically occurs only in animals fed particular types of diets and perhaps even in particular animal species. This appears to be the case with $V$. parvula (formerly $V$. gazogenes) (9), a succinate and lactate fermenter that has not been found to be numerically important except in sheep rumina. Similarly, lactate-fermenting sarcinas have been found to be important only in cows fed production diets containing grass silage (18). More work will have to be done before it can be determined whether the presence of Succiniclasticum ruminis in the rumen biota is related to diet.

\section{ACKNOWLEDGMENTS}

I thank Erik Lindgren for unwavering moral support and Barbro Näslund for the high-performance liquid chromatography analysis. F. A. Rainey (DSM-Deutsche Sammlung von Mikroorganismen, Braunschweig, Germany) provided nucleotide sequences of $16 \mathrm{~S}$ ribosomal DNAs, the similarity matrix (Table 2), and the phylogenetic tree (Fig. 3). H. Hippe (DSM-Deutsche Sammlung von von Mikroorganismen) supplied the micrograph (Fig. 2).

\section{REFERENCES}

1. Andersson, R., and B. Hedlund. 1983. HPLC analysis of organic acids in lactic acid fermented vegetables. Z. Lebensm. Unters. Forsch. 176:440-443.

2. Blackburn, T. H., and R. E. Hungate. 1963. Succinic acid turnover and propionate production in the bovine rumen. Appl. Microbiol. 11:132-135.

3. Cook, G. M., F. A. Rainey, G. Chen, E. Stackebrandt, and J. B. Russell. 1994. Emendation of the description of Acidaminococcus fermentans, a trans-aconitate- and citrate-oxidizing bacterium. Int. J. Syst. Bacteriol. 44:576-578.

4. Del Dot, T., R. Osawa, and E. Stackebrandt. 1993. Phascolarctobacterium faecium gen. nov., spec. nov., a novel taxon of the Sporomusa group of bacteria. Syst. Appl. Microbiol. 16:380-384.

5. De Soete, G. 1983. A least squares algorithm for fitting additive trees to proximity data. Psycometrika 48:621-626.

6. Hippe, H. (Deutsche Sammlung von Mikroorganismen und Zellkulturen). 1994. Personal communication

7. Holdeman, L. V., E. P. Cato, and W. E. C. Moore (ed.). 1977. Anaerobe laboratory manual, 4th ed. Virginia Polytechnic Institute and State University, Blacksburg.

8. Hungate, R. E. 1966. The rumen and its microbes. Academic Press, Inc., New York.

9. Johns, A. T. 1951. Isolation of a bacterium, producing propionic acid, from the rumen of sheep. J. Gen. Microbiol. 5:317-325.

10. Jukes, T. H., and C. R. Cantor. 1969. Evolution of protein molecules, p 21-132. In H. N. Munro (ed.), Mamalian protein metabolism. Academic Press, New York.

11. Rainey, F. A., M. Dorsch, H. W. Morgan, and E. Stackebrandt. 1992. 16 S rDNA analysis of Spirochaeta thermophila: positions and implications for the systematics of the order Spirochaetales. Syst. Appl. Microbiol. 16:224-226.

12. Rainey, F. A., and E. Stackebrandt. 1993. 16S rDNA analysis reveals phylogenetic diversity among the polysaccharolytic clostridia. FEMS Microbiol. Lett. 113:125-128.

13. Schink, B., and N. Pfennig. 1982. Propionigenium modestum gen. nov., sp. nov., a new strictly anaerobic, nonsporing bacterium growing on succinate. Arch. Microbiol. 133:209-216.

14. Thauer, R. K., K. Jungermann, and K. Decker. 1977. Energy conservation in chemotrophic anaerobic bacteria. Bacteriol. Rev. 41:100-180.

15. van Gylswyk, N. O. 1990. Enumeration and presumptive identification of some functional groups of bacteria in the rumen of dairy cows fed grass silage-based diets. FEMS Microbiol. Ecol. 73:243-253.

16. van Gylswyk, N. O. 1993. Unpublished data.

17. van Gylswyk, N. O., and J. J. T. K. van der Toorn. 1987. Clostridium aerotolerans sp. nov., a xylanolytic bacterium from corn stover and from the rumina of sheep fed corn stover. Int. J. Syst. Bacteriol. 37:102-105.

18. van Gylswyk, N. O., and C. E. A. van Doorn. 1992. Incidence and some growth characteristics of lactate-fermenting ruminal sarcinas. Swed. J. Agric. Res. 22:131-139.

19. Wolin, M. J., and T. L. Miller. 1988. Microbe-microbe interactions, p. 343359. In P. N. Hobson (ed.), The rumen microbial ecosystem. Elsevier Applied Science, London. 